\title{
EDUCAÇÃO, LAZER E SOCIABILIDADE: memórias e representações sobre a Praça do Imigrante em São Leopoldo / RS (1924-1960)
}

EDUCACIÓN, OCIO Y SOCIABILIDAD: memorias y representaciones sobre la Praça do Imigrante en São Leopoldo / RS (1924-1960)

\section{EDUCATION, LEISURE AND SOCIABILITY: memories and representations about Praça do Imigrante in São Leopoldo / RS (1924-1960)}

\author{
Estela Denise Schütz Brito' \\ https://orcid.org/0000-0003-3311-9975
}

Ariane dos Reis Duarte 2 https://orcid.org/0000-0001-6599-5393

\begin{abstract}
Resumo
Esta pesquisa tem como objeto de estudo a Praça do Imigrante, localizada na cidade considerada o berço da colonização alemã, São Leopoldo / RS. Em relação aos pressupostos teóricos, a pesquisa está ancorada nos estudos e conceitos vinculados ao campo da História Cultural (CHARTIER, 1990; 2011) e da Geografia Urbana (CARLOS, 2007). Tem como objetivo analisar aspectos relacionados ao espaço denominado de Praça do Imigrante. Como objetivos específicos, busca apontar suas mudanças e transformações no decorrer do tempo e identificar as representações sobre tal espaço nas memórias de sujeitos que o frequentaram no recorte temporal estabelecido. Para isso, foram mobilizados 13 registros fotográficos da praça em diferentes temporalidades, além de narrativas de memórias de alunos que estudaram em regime de internato na Escola Normal Evangélica (ENE) entre as décadas de 1950 e 1960. No decorrer do estudo, foram evidenciadas as transformações ocorridas no espaço da Praça, fruto das intervenções feitas ao longo dos anos. Nesse sentido, observou-se, também, certo afastamento do público em relação a tal espaço. Quanto às memórias dos estudantes da ENE, verificou-se que as práticas escolares e os usos da praça pelos estudantes interligavam o espaço público da praça ao espaço privado da escola, representando, por meio das narrativas, a praça enquanto um espaço de educação, lazer e sociabilidade.
\end{abstract}

Palavras-chave: Praça do Imigrante. São Leopoldo. Memória. Sociabilidade.

\footnotetext{
${ }^{1}$ Doutoranda em Educação pelo Programa de Pós-Graduação em Educação da Universidade do Vale do Rio dos Sinos (UNISINOS). Bolsista taxa - Capes/Proex. Membro do grupo de pesquisa "Educação no Brasil: memória, instituições e cultura escolar" (Ebramic). E-mail: schutzbrito@gmail.com

${ }^{2}$ Doutora em Educação. Professora substituta na Faculdade de Educação da Universidade Federal do Rio Grande do Sul/UFRGS. Membro do grupo de pesquisa "Educação no Brasil: memória, instituições e cultura escolar" (Ebramic).E-mail: ariane.reisd@gmail.com
}

\section{Como referenciar este artigo:}

BRITO, E. D. S.; DUARTE, A. R. Educação, lazer e sociabilidade: memórias e representações sobre a Praça do Imigrante em São Leopoldo / RS (1924-1960). Revista Pedagógica, v. 23, p. 1-25, 2021. 


\title{
Resumen
}

Esta investigación tiene como objeto de estudio la Praça do Imigrante ubicada en la ciudad de São Leopoldo, considerada cuna de la inmigración alemana, en Rio Grande do Sul. En relación a los supuestos teóricos, esta investigación se ancla en estudios y conceptos vinculados al campo de la Historia Cultural (CHARTIER, 1990; 2011) y la Geografía Urbana (CARLOS, 2007). Tiene como objetivo analizar aspectos relacionados con el espacio denominado Praça do Imigrante y, como objetivos específicos, señalar sus cambios y transformaciones en el tiempo, además de identificar las representaciones sobre dicho espacio en la memoria de los sujetos que lo asistieron en el marco temporal establecido. Para ello, se movilizaron 13 registros fotográficos de la plaza, en diferentes momentos, también narrativas de la memoria de los alumnos que estudiaron, em régimen de internado, en la Escola Normal Evangélica (ENE), entre las décadas de 1950 y 1960. Las transformaciones que se han producido en el espacio de la Praça son evidentes, fruto de las intervenciones a lo largo de los años. Delante de eso, existía una cierta distancia del público en relación a este espacio. En cuanto a las memorias de los alumnos de la ENE, se encontró que las prácticas escolares y los usos de la plaza por parte de los alumnos interconectaban el espacio público de la plaza con el espacio privado de la escuela, representando, a través de las narrativas, la plaza como espacio de educación, ocio y sociabilidad.

Palabras clave: Praça do Imigrante. São Leopoldo. Memoria. Sociabilidad.

\begin{abstract}
This research has as object of study the square named Praça do Imigrante, located in the city considered the birthplace of German immigration, São Leopoldo/RS. Regarding the theoretical assumptions, this research is anchored in the studies and concepts linked to-Cultural History (CHARTIER, 1990; 2011) and Urban Geography (CARLOS, 2007). It aims to analyze aspects related to the space called Praça do Imigrante and, as specific objectives, point out its changes and transformations over time and identify the representations about this space in the memories of subjects who used to go to this place in the established time frame. To this end, 13 photographic records of the square at different times were collected, in addition to narratives of the memories of students who attended the boarding school Escola Evangélica Normal (ENE) between the 1950 s and 1960s. The changes that occurred within the square area due to interventions over the years were highlighted. In this sense, there was a certain distance from the public in relation to this space. About memories students' ENE, the school practices and the uses of the square by the students interconnected public space of square with private space of the school, representing, through the narratives, the square as a space for education, leisure, and sociability.
\end{abstract}

Keywords: Praça do Imigrante. São Leopoldo. Memory. Sociability.

\section{CONSIDERAÇÕES INICIAIS}

Este texto tem como objeto de análise a chamada Praça do Imigrante, situada no município de São Leopoldo. Esta, por sua vez, localiza-se na região metropolitana de Porto Alegre/RS e é considerada "O berço da colonização alemã", por ter sido nessa região que os primeiros imigrantes alemães desembarcaram em 1824. Este 
acontecimento passa a ser o ponto de sustentação da história e memória de São Leopoldo e da região do Vale do Rio dos Sinos, onde são priorizadas as narrativas em torno da imigração alemã em detrimento de outras possíveis. Para isso, a construção dos lugares de memória tem um papel determinante, pois operam sob a lógica de que:

Não há memória espontânea, que é preciso criar arquivos, que é preciso manter aniversários, organizar celebrações, pronunciar elogios fúnebres, notariar atas, porque essas operações não são naturais [...] sem vigilância comemorativa, a história depressa os varreria (NORA, 1993, p. 13).

A Praça do Imigrante, situada na região central da cidade, foi construída com o intuito de ser um ponto de referência no que diz respeito à imigração alemã. Para isso, o espaço escolhido para sua edificação não poderia ser outro: às margens do Rio dos Sinos, local de chegada dos imigrantes alemães, ao lado da ponte 25 de julho e em frente à Igreja Matriz Nossa Senhora da Conceição³. Este conjunto, erigido no decorrer do processo de colonização e expansão do município, passou a compor a paisagem da região do desembarque dos imigrantes chegados na primeira metade do século XIX e, hoje, é parte do centro histórico de São Leopoldo.

Assim, este texto toma a Praça do Imigrante como objeto e propõe pensar as relações estabelecidas com este lugar no recorte temporal estabelecido, que se refere ao momento da construção da mesma e às narrativas de memórias que compõem o acervo empírico por nós mobilizado. Este é composto por seis narrativas de memórias ${ }^{4}$ produzidas com alunos que estudaram em regime de internato na Escola Normal Evangélica5 entre as décadas de 1950 e 1960. As narrativas foram produzidas, entre os anos de 2016 e 2017, a partir dos preceitos metodológicos da História Oral. Além disso, dispomos de 13 registros fotográficos do espaço da praça em diferentes temporalidades, dos quais, cinco aparecerão no decorrer do trabalho. Alguns destes documentos foram disponibilizados pelos entrevistados, outros coletados junto ao site do Instituto Brasileiro

\footnotetext{
${ }^{3}$ A Igreja Matriz Nossa Senhora da Conceição foi construída originalmente pelos imigrantes alemães. O mesmo ocorre com a Ponte 25 de julho, construída entre 1871 e 1876. Com informações de: <https://biblioteca.ibge.gov.br/index.php/biblioteca-catalogo?id=446001\&view=detalhes> <http://www.belgianclub.com.br/pt-br/heritage/ponte-25-de-julho-s\%C3\%A3o-leopoldo . Acesso em: 24 maio 2021.

4 Declaramos que foram tomados todos os cuidados éticos na produção e análise da empiria aqui apresentada.

${ }^{5}$ Instituição confessional evangélica, que funcionou em regime de internato misto de 1926 a 1966 na cidade de São Leopoldo/RS, instalada nos prédios ao lado da Praça do Imigrante (BRITO, 2018).
} 
de Geografia e Estatística (IBGE) e, ainda, contamos com fotografias que angariamos em acervos disponibilizados em redes sociais.

A partir da construção deste acervo empírico, tomamos como pressupostos teóricos os estudos do campo da História Cultural (CHARTIER, 1990; 2011) e da Geografia Urbana (CARLOS, 2007), que nos ajudaram a tensionar questões a respeito deste local de referência na cidade. Assim, este texto tem como objetivo geral analisar aspectos relacionados ao espaço denominado de Praça do Imigrante e, como objetivos específicos, apontar suas mudanças e transformações no decorrer do tempo e identificar as representações sobre tal espaço nas memórias de sujeitos que o frequentaram no recorte temporal estabelecido.

Nesse sentido, o artigo está organizado da seguinte forma: inicialmente, apresentamos os aportes teóricos e metodológicos que sustentam a pesquisa. Em seguida, apresentamos um breve contexto histórico da cidade e da praça em específico e, para isso, recorremos às noções e conceitos propostos pelo campo dos estudos geográficos. Desse modo, abordamos as mudanças ocorridas na Praça do Imigrante e arredores no decorrer do tempo. Na sequência, apresentamos a discussão sobre a praça como um espaço de sociabilidade (FONTES, 2018), tensionando seus usos e memória construída a respeito deste local. Por fim, apresentamos nossas considerações finais e referências utilizadas para o estudo.

\section{CAMINHOS TEÓRICOS E METODOLÓGICOS DA PESQUISA}

A História da Educação vem, nas últimas décadas, ampliando seus estudos e campo de interesses, travando diálogos com diferentes áreas do conhecimento. Para além das pesquisas voltadas à História, as interlocuções com autores e estudos da Sociologia, Antropologia, Geografia, Filosofia e das Artes têm sido observadas nas pesquisas acadêmicas de Mestrado e Doutorado ${ }^{6}$.

Essas aproximações com as diferentes áreas e a profusão de temáticas distintas foram propiciadas pelo campo da História Cultural. Nessa direção, conforme os

\footnotetext{
${ }^{6}$ Dentre as pesquisas, destacamos os trabalhos desenvolvidos por Mayboroda (2017) e Duarte (2019).
} 
ISSN 1984-1566 (on-line) ISSN 1415-8175 (impressa)

historiadores franceses Jacques Le Goff (1974) e Pierre Nora (1974) provocaram a pensar, “[...] novos problemas, novas abordagens e novos objetos" começaram a surgir. Temas antes observados como periféricos, receberam visibilidade no campo (BURKE, 1992). Assim como temas e objetos, as fontes documentais também se ampliaram, e um leque com diferentes possibilidades investigativas, a partir de diferentes materialidades, abriram-se aos pesquisadores.

Posto isto, ao compor este artigo, optamos por tratar o objeto de estudo abordado concatenando conceitos de diferentes áreas do campo das ciências humanas. Assim, iremos mobilizar determinados pressupostos da Geografia urbana, sobretudo no que tange à composição das cidades, para discutir aspectos da transformação da praça. Posteriormente, provocadas por Demartini (2013), fomos além, buscando informações onde elas pudessem estar guardadas, ou seja, recorreremos às memórias de sujeitos que, quando jovens estudantes, frequentaram o local no recorte temporal estabelecido. Tais memórias serão tensionadas e discutidas a partir das noções de representação e sociabilidade.

Para a produção das narrativas de memória desses seis alunos que estudaram em regime de internato na ENE, seguimos os preceitos da metodologia da História Oral. Thompson (1992, p. 44), explica que “[...] a história oral é uma história construída em torno de pessoas. Ela lança a vida para dentro da própria história e isso alarga seu campo de ação". Ou seja, ela dinamiza a história, pois gira em torno de vidas e continua a explicar que esta forma de trabalho "[...] admite heróis não só dentre os líderes, mas dentre a maioria desconhecida do povo" (1992, p. 44). Partindo dessa premissa, entendemos ser importante apresentar os partícipes deste estudo, uma vez que eles são os protagonistas da história a ser contada. Dessarte, após eles assinarem um termo livre e esclarecido, autorizando o uso de sua identidade, sistematizamos as informações dos entrevistados em um quadro para identificá-los:

Quadro 1 - Relação das entrevistas e entrevistados 
Revista do Programa de Pós-Graduação em Educação da Unochapecó

ISSN 1984-1566 (on-line) ISSN 1415-8175 (impressa)

\begin{tabular}{|c|c|c|c|c|c|c|}
\hline \multicolumn{7}{|c|}{ DADOS DOS ENTREVISTADOS E DAS ENTREVISTAS } \\
\hline NOME & $\begin{array}{c}\text { DATA DE } \\
\text { NASCIMENTO/IDADE }\end{array}$ & CIDADE NATAL & $\begin{array}{l}\text { PERÍODO DE } \\
\text { INTERNATO }\end{array}$ & $\begin{array}{l}\text { DIA E LOCAL DA } \\
\text { ENTREVISTA }\end{array}$ & $\begin{array}{c}\text { TEMPO DE } \\
\text { ENTREVISTA }\end{array}$ & $\begin{array}{l}\text { NÚMERO DE } \\
\text { PÁGINAS } \\
\text { TRASCRITAS }\end{array}$ \\
\hline Celene Thoen & $\begin{array}{l}17 \text { de fevereiro de } 1944 \\
\text { (74 anos) }\end{array}$ & $\begin{array}{l}\text { Entrepelado, } \\
\text { distrito de } \\
\text { Taquara/RS }\end{array}$ & $1958-1962$ & $\begin{array}{l}\text { 30/o8/2018, em sua } \\
\text { residência em } \\
\text { Campo Bom/RS }\end{array}$ & $01: 04: 38$ & 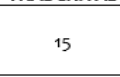 \\
\hline Danilo Romeu Streck & $\begin{array}{l}11 \text { de maio de } 1948 \\
(69 \text { anos })\end{array}$ & $\begin{array}{l}\text { Caemborá, distrito } \\
\text { de Nova Palma/RS }\end{array}$ & $1961-1965$ & $\begin{array}{l}\text { 01/12/2016 em São } \\
\text { Leopoldo/RS, no seu } \\
\text { gabinete na } \\
\text { Unisinos }\end{array}$ & $56: 44$ & 15 \\
\hline $\begin{array}{l}\text { Helga Elisabeth } \\
\text { Porcher }\end{array}$ & $\begin{array}{l}31 \text { de dezembro de } 1943 \\
\text { (74 anos) }\end{array}$ & Venâncio Aires/RS & $1958-1961$ & $\begin{array}{c}\text { 20/10/2017 em Porto } \\
\text { Alegre/RS, na sua } \\
\text { residência }\end{array}$ & 1:17:30 & 20 \\
\hline $\begin{array}{l}\text { Hermedo Egidio } \\
\text { Wagner }\end{array}$ & $\begin{array}{c}8 \text { de março de } 1936 \\
\text { (81 anos) }\end{array}$ & $\begin{array}{c}\text { Sinimbu, distrito de } \\
\text { Santa Cruz do } \\
\text { Sul/RS } \\
\end{array}$ & $1950-1953$ & $\begin{array}{c}26 / 09 / 2017 \mathrm{em} \\
\text { Ivoti/RS, na sua } \\
\text { residência }\end{array}$ & 1:49:58 & 21 \\
\hline $\begin{array}{l}\text { Luiz Alberto Mário } \\
\text { Bencke }\end{array}$ & $\begin{array}{l}14 \text { de março de } 1945 \\
\text { (72 anos) }\end{array}$ & Venâncio Aires/RS & $1961-1964$ & $\begin{array}{l}25 / 10 / 2016, \text { em } \\
\text { Ivoti/RS, na sua } \\
\text { residência }\end{array}$ & $1: 23: 37$ & 23 \\
\hline Roswitha Dreher & $\begin{array}{l}11 \text { de agosto de } 1945 \\
\text { (72 anos) }\end{array}$ & $\begin{array}{l}\text { Três de Maio, } \\
\text { distrito de Santa } \\
\text { Rosa/RS } \\
\end{array}$ & $1958-1962$ & $\begin{array}{l}\text { O2/02/2017, em } \\
\text { Porto Alegre/RS na } \\
\text { sua residência. }\end{array}$ & 4:03:43 & 42 \\
\hline
\end{tabular}

Fonte: Organizado pelas autoras (2021).

Seguindo os passos sugeridos pela metodologia, as entrevistas foram gravadas em aparelho sonoro com cada participante, transcritas e realizadas a sua devolução, transformando, assim, a oralidade em documento escrito. Cabe salientar ainda que as cenas rememoradas, as imagens e os acontecimentos narrados nas entrevistas de história oral acabam sendo uma reconstrução, uma representação de como esse sujeito que narra acredita ter sido tal experiência. Não quer dizer que o narrador esteja mentindo, criando ou inventando sua história; muito pelo contrário, o sujeito que narra busca "[...] dizer não a verdade, mas a sua verdade, mesmo que o façam com maior ou menor cooperação e boa-fé" (VOLDMAN, 2006, p. 264).

Além das narrativas de memórias, o material empírico é composto por um acervo construído pelas pesquisadoras com fotografias que retratam o espaço da Praça do Imigrante em diferentes temporalidades, contribuindo como uma potente fonte para problematizar e refletir sobre as transformações dos cenários ao longo das décadas. Cabe mencionar que, embora não tenha sido possível identificar o ano preciso das fotografias, tivemos o cuidado de analisá-las e selecionar aquelas que estivessem dentro do recorte temporal estabelecido neste texto. Sobre essa categoria documental, Ulpiano T. Bezerra de Meneses (2003, p. 29) salienta que:

O emprego de imagens como fonte de informação é apenas um dentre tantos (inclusive simultaneamente a outros) e não altera a natureza da coisa, mas se realiza efetivamente em situações culturais específicas, entre várias outras. A mesma imagem, portanto, pode reciclar-se, assumir vários papéis, ressemantizar-se e produzir efeitos diversos (MENESES, 2003, p. 29). 
ISSN 1984-1566 (on-line) ISSN 1415-8175 (impressa)

Por conseguinte, assim como as narrativas de memórias, compreendemos os registros fotográficos da praça como representações deste espaço, uma vez que o registro fotográfico corresponde a uma ação humana carregada de intenções. Para Ana Maria Mauad (2005, p. 136), “[...] há de se considerar a fotografia como uma determinada escolha realizada num conjunto de escolhas possíveis, guardando nessa atitude uma relação estreita com a visão de mundo daquele que aperta o botão e faz clique". A escolha do espaço, do ângulo e do enfoque é proveniente da intenção do sujeito que fotografa, de modo que tal ação é atravessada pelas concepções e vontades deste. Assim, entendemos que um conceito chave para a exploração do acervo empírico por nós constituído é a noção de representação (CHARTIER, 1990), que pode ser definida como “[...] esquemas intelectuais incorporados que criam as figuras graças às quais o presente pode adquirir sentido, o outro tornar-se inteligível e o espaço ser decifrado" (CHARTIER, 1990, p. 17). Portanto, a representação não é a realidade em si, mas sim aquilo que cada indivíduo interpreta sobre determinado fato e/ou realidade.

As transformações produzidas no espaço que abriga a praça inserem-se no processo de urbanização de São Leopoldo. Como construção humana, as cidades são fruto de ações acumuladas ao longo do tempo e, com isso, são portadoras e reveladoras de intenções de determinados grupos que a habitaram no passado. Como espaço onde se desenrola a vida cotidiana, a cidade e seus lugares vão ganhando novos sentidos e significados que se modificam de acordo com a passagem do tempo.

Expressão e significação da vida humana, a cidade a revela ao longo da história, como obra e produto que se efetiva como realidade espacial concreta em um movimento cumulativo, incorporando ações passadas ao mesmo tempo em que aponta as possibilidades futuras que se tecem no presente da vida cotidiana (CARLOS, 2007, p. 20).

Pensar o espaço da praça como uma área de sociabilidade, de troca entre os sujeitos, de criação de laços afetivos, faz todo o sentido nesse contexto, uma vez que História, espaço e sociedade se complementam, assim como explica Milton Santos: “[...] a História não se escreve fora do espaço e não há sociedade a-espacial. O espaço, ele mesmo é social" (SANTOS, 1979, p. 10). Para este autor, o espaço se forma a partir de um conjunto de relações, constituídas por ações do passado e do presente, ou seja: 
[...] o espaço se define como um conjunto de formas representativas de relações sociais do passado e do presente e por uma estrutura representada por relações sociais que estão acontecendo diante dos nossos olhos e que se manifestam através de processos e funções (SANTOS, 2004, p. 153).

Essas relações, destacadas por Santos (2004), podem ser compreendidas como movimentos de interação entre indivíduos, isto é, formas de sociabilidade. Neste sentido, é importante ainda enfatizar que o conceito de sociabilidade tem sua origem nos estudos do sociólogo alemão Georg Simmel (1858-1918). Em seus estudos, Simmel (1983) aponta que a sociabilidade é como uma forma lúdica e autônoma do conceito de sociação, argumentando que:

[...] aqui "sociedade" propriamente dita é o estar com um outro, para um outro, contra um outro que, através do veículo dos impulsos ou dos propósitos, forma e desenvolve os conteúdos e os interesses materiais ou individuais. As formas nas quais resulta esse processo ganham vida própria. São liberadas de todos os laços com os conteúdos; existem por si mesmas e pelo fascínio que difundem pela própria liberação destes laços. É isto precisamente o fenômeno a que chamamos sociabilidade (SIMMEL, 1983, p. 168).

Em vista disso, provocadas pelas reflexões de Santos (1979; 2004) e Simmel (1983), propomo-nos nessa escrita a olhar para esse espaço da Praça do Imigrante como uma instância de sociabilidade consolidado na história da cidade de São Leopoldo. A partir do conjunto de narrativas de memórias que iremos apresentar no decorrer deste estudo, percebemos que o estar na praça para os estudantes da ENE era um momento e uma oportunidade de "estar com o outro, para o outro e contra um outro".

\section{CONTEXTO HISTÓRICO}

Segundo dados do Instituto Brasileiro de Geografia e Estatística/IBGE (2010), São Leopoldo integra a região metropolitana de Porto Alegre, capital do estado do Rio Grande do Sul. A população estimada é de 238.648 habitantes distribuídos nos 24 bairros que compõem o município. O índice de desenvolvimento humano é de 0,739 (ver fonte de dados $)^{7}$, o que indica que a cidade possui características e demandas semelhantes aos demais centros urbanos do país. Embora seu conjunto populacional seja diverso, devido

7 Os dados foram extraídos de: <https://www.ibge.gov.br/cidades-e-estados/rs/sao-leopoldo.html> e $<$ https://www.saoleopoldo.rs.gov.br/?template=abreAnexos\&arquivo=9211\&nomeArquivo=MAPA\%20MUNI CIPAL\%20S\%C3O\%20LEOPOLDO\%2003.08.18\&categoriaDownload=9>. Acesso em: 01 maio. 2021. 
ISSN 1984-1566 (on-line) ISSN 1415-8175 (impressa)

aos fluxos migratórios característicos do processo de urbanização, a narrativa em torno da colonização segue sendo explorada como fio condutor da história do município. Desse modo, anualmente, celebra-se o 25 de julho, data do desembarque dos imigrantes alemães, com a São Leopoldo Fest, evento que contempla música, feiras, shows e diversas referências ao que supostamente seria a cultura alemã.

Figura 1- Região metropolitana de Porto Alegre com São Leopoldo em destaque

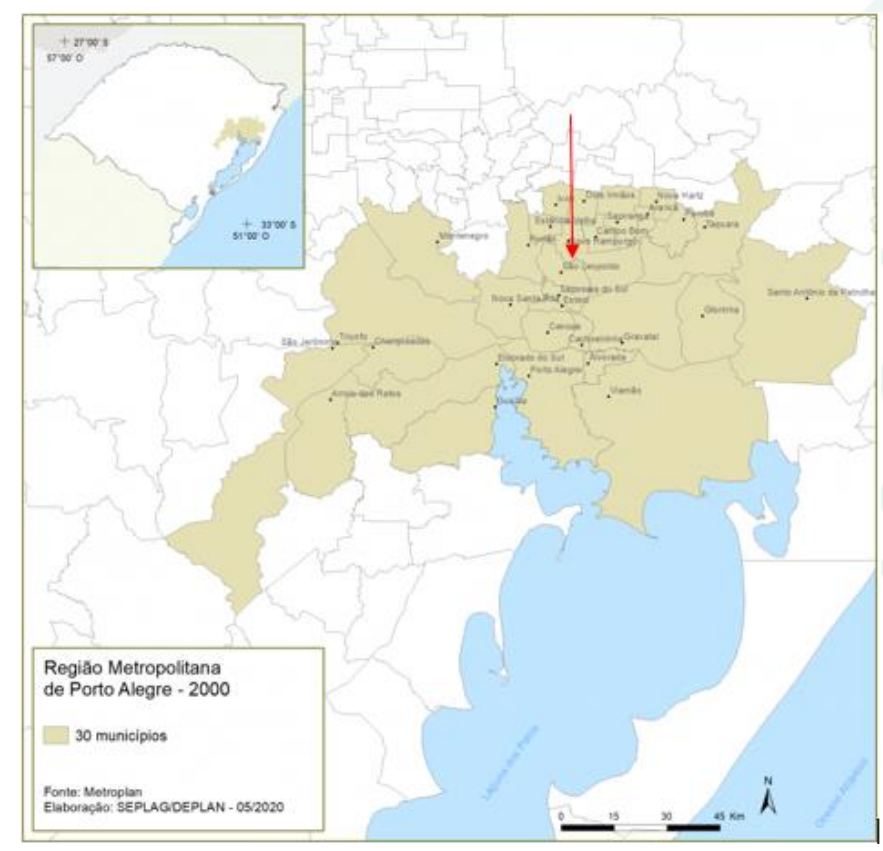

Fonte: Atlas Socioeconômico do Rio Grande do Sul ${ }^{8}$ [grifo nosso].

No ano de 2011, São Leopoldo passa a ser oficialmente reconhecida pela alcunha “Berço da colonização alemã”. Tal oficialização é parte do movimento que acaba por priorizar a imigração alemã como marco para a história e memória da região. Embora não seja o enfoque deste estudo, consideramos importante mencionar o fato de que o esforço por forjar uma memória a respeito da imigração implica em esquecimentos e silenciamentos, pois as demais populações que habitaram a região não ganham a mesma atenção daqueles que se engajam por trabalhar a história considerando este viés, como apontam os estudos de Magalhães (2010) e Travi (2018).

Diante disso, é importante esclarecer que a região que abriga o município de São Leopoldo fora anteriormente local habitado pelos povos originários, como os Kaigangs e

${ }^{8}$ Disponível em: <https://atlassocioeconomico.rs.gov.br/midia/imagem/map-2000-rmpa-rs>. Acesso em: 08 maio 2021. 


\section{Revista do Programa de Pós-Graduação em Educação da Unochapecó}

ISSN 1984-1566 (on-line) ISSN 1415-8175 (impressa)

os Carijós. Com o avanço da ocupação do território da região sul do país no século XVIII, nesta localidade passou a funcionar uma fazenda estatal de produção de cordas para navios. Tal empreendimento funcionava com base na mão de obra de africanos escravizados e esteve em atividade até as vésperas da chegada dos imigrantes alemães. Como se pode observar, outros grupos étnicos estiveram presentes na composição da região, no entanto, até o momento, a historiografia local não se deteve pontualmente em tais questões, tampouco há lugares de memória que enfatizem estes aspectos.

Entre os movimentos realizados para consolidar a memória em torno da imigração, estão a construção de monumentos e espaços de sociabilidade. Desse modo, no centenário da imigração alemã, em 1924, inicia-se a construção de um monumento para celebrar tal fato em um aterro situado na região central do município. A construção homenageia os imigrantes chegados em 1824 e é inaugurada com festejos e celebrações. Segundo Weber (2016), a construção do monumento foi financiada pela sociedade civil e pelo município de São Leopoldo. Na fotografia 1, há um aspecto da paisagem desta região durante a construção do monumento, que foi inaugurado mesmo não estando finalizado.

Fotografia 1 - Aterro com o monumento ao Imigrante e prédios ao fundo

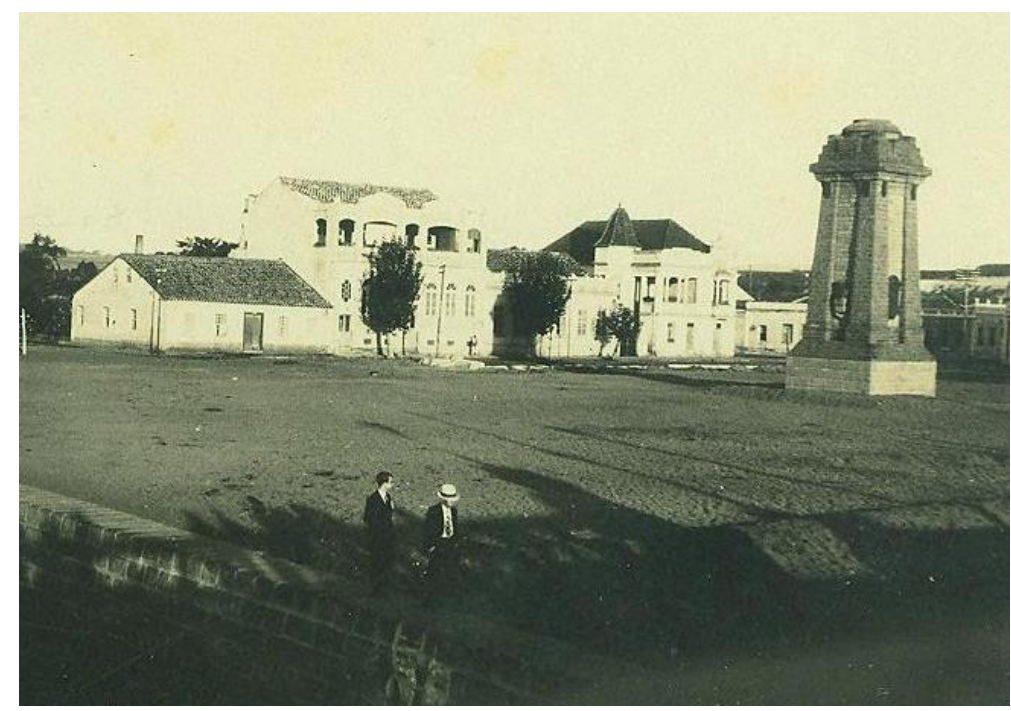

Fonte: Museu Histórico Visconde de São Leopoldo (Ano: 192?).

Como se pode observar, a fotografia 1 evidencia o cenário de uma cidade em um tímido processo de desenvolvimento. A presença de prédios nos arredores do aterro revela as transformações promovidas na região, que aos poucos vai ganhando contornos

\footnotetext{
9 Fotografia retirada na página do Facebook do Museu Histórico Visconde de São Leopoldo, disponível em:
} <https://www.facebook.com/mhvsl/posts/1110309625783995/>. Acesso em: 24 maio 2021. 


\section{Revista do Programa de Pós-Graduação em Educação da Unochapecó}

ISSN 1984-1566 (on-line) ISSN 1415-8175 (impressa)

moderadamente urbanizados. O local onde o monumento foi erguido é um aterro que surgiu a partir da modificação do curso e presença do Rio dos Sinos, cujas águas chegaram a alcançar até aquele ponto. No canto esquerdo da imagem e com certo destaque na composição geral, vemos o prédio que virá a ser o espaço da Escola Normal Evangélica, e sua relação com a praça será tratada nas seções a seguir.

Posteriormente, o local que abriga o monumento passa a ser o espaço destinado à construção da Praça Centenário (chamada Praça do Imigrante a partir de 1965), inaugurada em 1934, na gestão do intendente municipal Theodomiro Porto da Fonseca ${ }^{10}$. Para a edificação de tal espaço, são feitas modificações na estrutura física deste ponto do município, como aterramento, construção de um cais, calçamento e ajardinamento (WEBER, 2016). Assim, com a construção da praça, a paisagem do local passa por intervenções que a fazem ter contornos mais definidos e, dessa forma, passa a compor uma espécie de cartão postal do município juntamente com as demais construções que remetem à colonização alemã. Na fotografia 2, observamos com detalhes tal composição:

Fotografia 2 - Centro histórico de São Leopoldo/RS

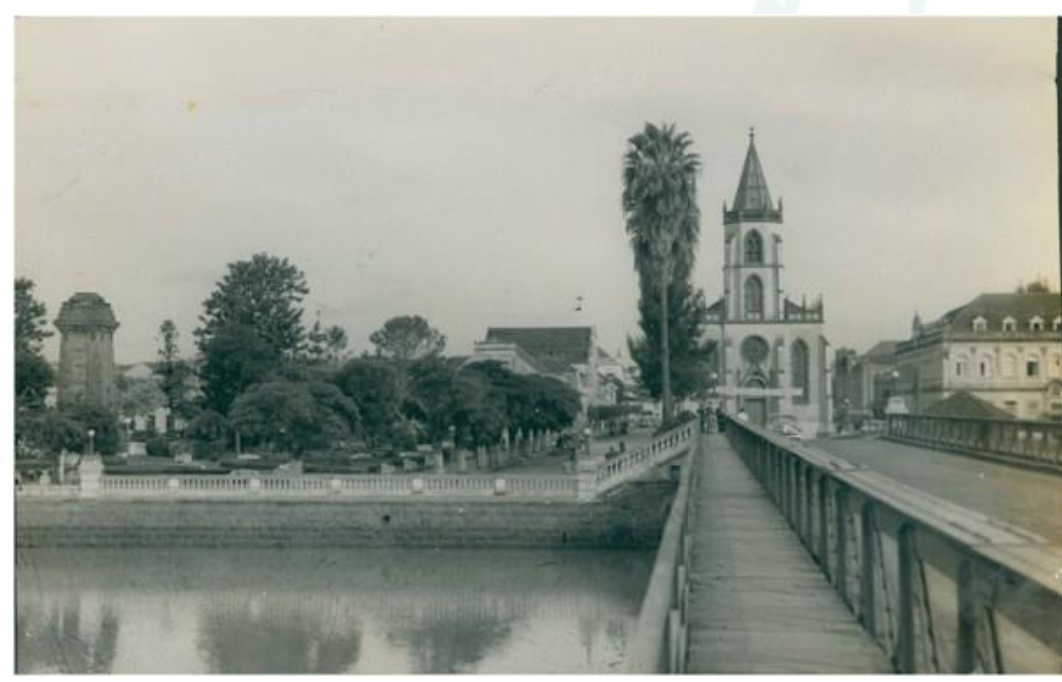

Fonte: IBGE' (Segunda metade do século XX).

Na fotografia 2, verifica-se a disposição das construções feitas às margens do Rio dos Sinos, local de desembarque dos primeiros imigrantes alemães. Ao fundo da imagem, da esquerda para a direita, temos a Praça Centenário, a Igreja Matriz Nossa Senhora da

\footnotetext{
${ }^{10}$ Theodomiro Porto da Fonseca (1879-1965) foi intendente municipal entre 1928 e 1944. Ao longo de sua administração, muitas obras foram realizadas em São Leopoldo, como a construção de uma nova sede para a prefeitura, um presídio municipal, a inauguração da BR 2 (atual BR 116), entre outras obras e edificações. ${ }^{11}$ Disponível em: <https://cidades.ibge.gov.br/brasil/rs/sao-leopoldo/historico>. Acesso em: 21 maio 2021.
} 


\section{Revista do Programa de Pós-Graduação em Educação da Unochapecó}

ISSN 1984-1566 (on-line) ISSN 1415-8175 (impressa)

Conceição, a Ponte 25 de julho e o prédio do Seminário Nossa Senhora da Conceição ${ }^{12}$. À frente, contornando todo o conjunto, está o rio, cujo alcance foi reduzido para a edificação das construções. Não foi possível detectar o ano em que a imagem foi produzida, mas o registro evidencia as mudanças promovidas no local, de modo que ficam claras as intervenções feitas para compor tal paisagem, assim como o avanço no processo de composição da paisagem da cidade.

Fotografia 3 - Vista aérea: Praça do Imigrante, Rio dos Sinos e prédios da Escola Normal Evangélica

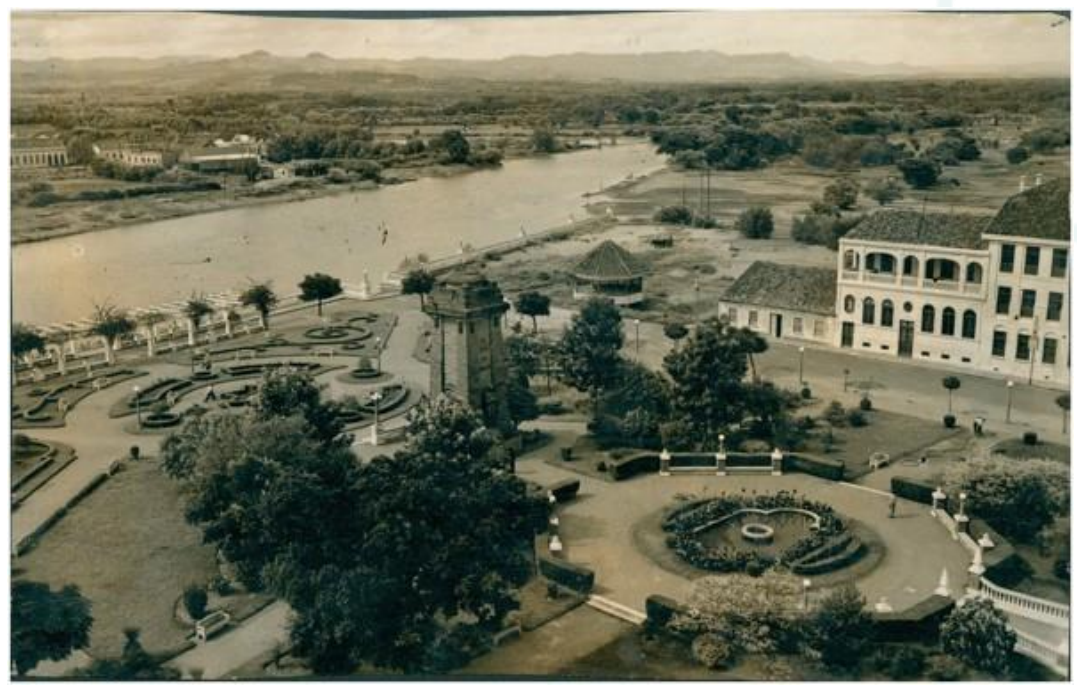

Fonte: IBGE ${ }^{13}$ (Segunda metade do século XX).

Na fotografia 3, temos uma vista aérea da praça e seus arredores em que fica evidenciada a presença do Rio dos Sinos ao fundo da imagem. Nessa composição, podemos perceber todas as modificações feitas no espaço da praça, tornando o lugar que antes era um aterro em um local de lazer, vivência e circulação. Embora não tenha sido possível identificar o ano em que a fotografia foi produzida, por meio dela é possível inferir que a relação dos transeuntes com o Rio era mais próxima, pois ele integra a paisagem da Praça, ajudando a compor a harmonia deste espaço e congregando com a intenção de tornar a Praça e seu monumento uma referência na história da colonização, já que os colonos alemães chegam até São Leopoldo por intermédio do rio.

\footnotetext{
${ }^{12}$ Este prédio abrigou o Ginásio Nossa Senhora da Conceição (1869-1912) e posteriormente o Seminário, com cursos de Filosofia e Teologia. Conforme informações extraídas de: <http://www.anchietano.unisinos.br/exposicao/historico.htm>. Acesso em: 20 maio 2021.

13 Fotografia disponível em: <https://cidades.ibge.gov.br/brasil/rs/sao-leopoldo/historico>. Acesso em: 21 maio 2021.
} 
Fotografia 4 - A praça em movimento

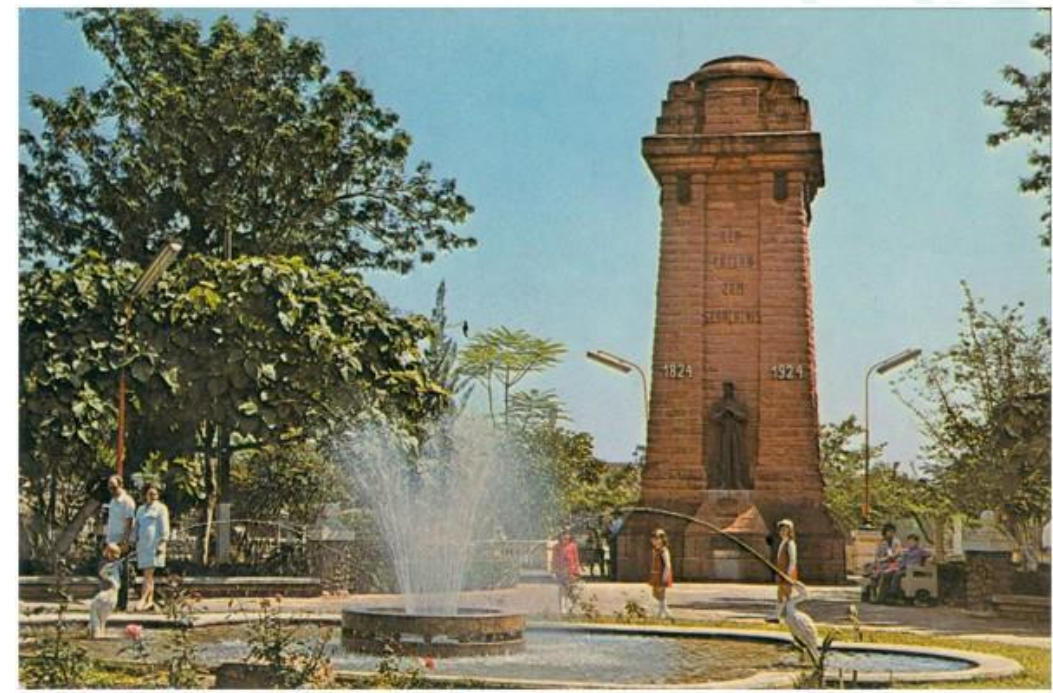

Fonte: IBGE ${ }^{14}$ (Segunda metade do século XX).

A fotografia 4 nos apresenta uma praça em movimento. Diferentemente das fotografias anteriores, nesta imagem podemos observar os diferentes usos do espaço público pela população, com a circulação de adultos e crianças, a praça como um espaço aparentemente de lazer e sociabilidade. A imagem com foco no centro da praça evidencia o chafariz em funcionamento, sendo a atração de crianças e seus familiares, além de apresentar, ao fundo, o monumento ao imigrante.

As transformações do cenário urbano, a partir do espaço da praça, são perceptíveis ao analisarmos os registros fotográficos em diferentes temporalidades. Quem passa pela praça do Imigrante nos dias de hoje pode se surpreender com as mudanças das paisagens provocadas com o passar dos anos e com o afastamento da população leopoldense em relação a este espaço e ao próprio Rio dos Sinos, que, como demonstrado pelas fotografias anteriores, tangencia a praça. Possivelmente, esse afastamento em relação à praça está relacionado ao aspecto que a mesma desenvolveu ao longo do tempo a partir da intervenção humana.

No decorrer dos anos, uma grande quantidade de árvores foi plantada em um espaço que era relativamente pequeno para abarcar estruturas de grande porte, o que passou a modificar totalmente sua aparência inicial. Isso fez com que a praça se tornasse

${ }^{14}$ Fotografia disponível em: <https://cidades.ibge.gov.br/brasil/rs/sao-leopoldo/historico>. Acesso em: 25 maio 2021. 
muito sombreada e até mesmo escurecida em determinados horários do dia, dificultando, assim, a permanência do público no local. Soma-se a isso a falta de segurança pública, que fez com que a praça configurasse um ambiente pouco atrativo para a circulação e o convívio, conforme a fotografia 5 apresenta:

Fotografia 5 - O espaço arborizado da praça

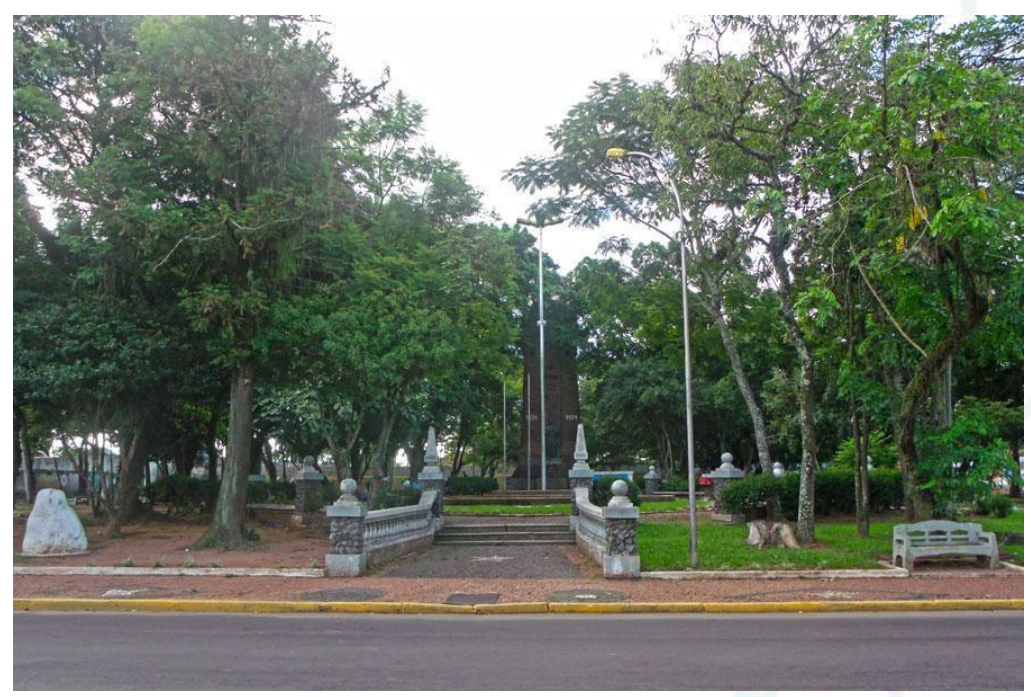

Fonte: Família Badini'15 (Ano: 200?).

Alguns movimentos foram realizados recentemente a fim de reaproximar a população leopoldense do espaço da praça. Limpeza do local e podas de árvores entraram nessas ações, buscando abrir o cenário e clarear o ambiente. Entretanto, tais iniciativas também colocaram a população em polos distintos. Se por um lado havia pessoas desejando que esse espaço fosse mais aberto e iluminado, por outro apareceram críticas e não aprovações para tais intervenções no espaço urbano ${ }^{16}$. Estes são aspectos gerais das relações dos leopoldenses com o espaço da praça na atualidade. No entanto, como exposto até aqui, nem sempre as relações com este lugar foram assim.

Na próxima seção, trataremos das memórias de sujeitos que, quando jovens estudantes da Escola Normal Evangélica, tiveram muitas vivências na praça e rememoram-na como um espaço significativo em suas atividades escolares.

\footnotetext{
${ }^{15}$ Disponível em: <http://www.badini.com.br/rs/sle/>. Acesso em: 23 maio 2021.

16 No ano de 2012, foi solicitado ao IPHAN - Instituto do Patrimônio Histórico e Artístico Nacional o tombamento do espaço. No entanto, os trâmites para sua consolidação ainda estão acontecendo. Nesse sentido, há um movimento para concretizar tal ação até 2024, ano do bicentenário da imigração. Em 2019, foi realizado um processo de revitalização da praça, tornando o espaço mais atrativo.
} 
Revista do Programa de Pós-Graduação em Educação da Unochapecó

ISSN 1984-1566 (on-line) ISSN 1415-8175 (impressa)

\section{A ESCOLA E A PRAÇA: EDUCAÇÃO, LAZER E SOCIABILIDADE}

Entre os anos de 1926 e 1966, instalou-se nos prédios ao lado da Praça do Imigrante e às margens do Rio dos Sinos o Seminário Evangélico de Formação de Professores Alemães. Os prédios para o funcionamento do Seminário foram adquiridos pela IECLB $^{17}$ e sua transferência da cidade de Santa Cruz do Sul para a cidade de São Leopoldo não ocorreu por acaso. O trecho publicado em 10 de abril de 1926 por um periódico que circulava entre a população alemã da região, Deutsche Post, descreve e elogia o local escolhido para a instalação do Seminário Evangélico, futura Escola Normal Evangélica:

Pela passagem do centenário da imigração, construiu-se um monumento de pedra, na Praça do Imigrante. Agora, criamos, com a transferência do Seminário, um ponto central, onde se cultivam os bens espirituais e culturais de nossos antepassados (HOPPEN, [19--], p. 38).

De forma estratégica, o Seminário de Formação de Professores Alemães, a Praça do Imigrante e o Rio dos Sinos estabeleceram essa tríade, unindo educação, lazer e cultura em torno do povo alemão no centro da cidade de São Leopoldo. Por forças do período de nacionalização do ensino ${ }^{18}$, o Seminário encontrou dificuldades para seu funcionamento. Suas atividades mantiveram-se em suspenso durante os anos de 1939 a 1949, quando então a instituição retomou seus trabalhos nos mesmos prédios em que o Seminário funcionava, agora sob o nome de Escola Normal Evangélica (ENE).

Por estar localizada ao lado da praça, alunos que moravam e estudavam na Escola Normal tinham esse espaço como uma extensão da escola. Foi na Praça do Imigrante que se desenvolveu parte de sua educação, de suas atividades práticas, de seus momentos de lazer, local onde estabeleciam conversas, estreitavam vínculos de amizade, formavam suas redes de sociabilidade, assim como aparece em suas narrativas de memórias desde sua chegada à instituição:

\footnotetext{
${ }^{17}$ Igreja Evangélica de Confissão Luterana no Brasil.

18 A campanha de nacionalização ocorreu durante o primeiro governo de Getúlio Vargas (1930-1945) e visava, segundo Xavier (2005), a um conteúdo nacional ao ensino, a uma padronização do mesmo e a uma erradicação das minorias étnicas, linguísticas e culturais que existiam no Brasil.
} 
"A escola que eu era para ir, ficava lá no morro no meio do mato, não era o prédio do Sinodal era o prédio do antigo IPT ${ }^{19}$, só que dois dias antes de sair de casa, eu recebi um fonograma, [...] que eu me apresentasse no prédio da Escola Técnica de Comércio que é o prédio antigo do Seminário. Aí eu fiquei contente, vibrei com aquilo. Eu tinha visto aquela foto que ficava numa praça, tinha um chafariz, monumento do imigrante. Assim, em fins de fevereiro de 1950, eu fui parar naquele instituto" (Hermedo Wagner, 2017).

A praça era um ponto de referência para os alunos quando se reportavam à escola. Roswitha Dreher, que estudou e morou durante cinco anos na ENE, também rememorou a praça (na ocasião denominada como Praça Centenário, conforme descrito anteriormente sobre mudanças de nomenclatura), para falar da sua moradia do internato:

\footnotetext{
"Pois é, eu queria ir para lá [Escola Normal] e o meu irmão estava em São Leopoldo, então a gente tinha assim uma... a gente se dava muito bem nos damos bem até hoje. Claro, ele morava ali em cima do moro [do Espelho], e eu morava lá embaixo na beira do rio, porque tem a praça centenário e tem uma quadra assim, tem o Grêmio Náutico lguaçú e daí é uma quadra, ainda hoje tem tipo assim um castelinho, numa esquina assim onde é a escola e a escola era mista" (Roswitha Dreher, 2017).
}

A fotografia 6 recompõe o cenário apresentado pelas narrativas de Hermedo e Roswitha. Nela, podemos observar uma praça com gramado e arbustos aparados, alguns bancos de concreto, um ambiente público aparentemente limpo, arborizado e bem cuidado, luminárias espalhadas pelo espaço, os prédios da Escola Normal aos fundos, a construção do Castelinho mais próximo ao canto direito da fotografia, o qual servia de moradia para o diretor da escola e sua família, e, bem ao centro da imagem, o chafariz da praça em funcionamento. Nesses fragmentos de memória, espaço público e privado aparecem entrelaçados, como se a praça se constituísse como uma continuidade do espaço escolar, como se este não se limitasse às paredes de sua construção.

Fotografia 6 - A Escola, a praça e o chafariz 


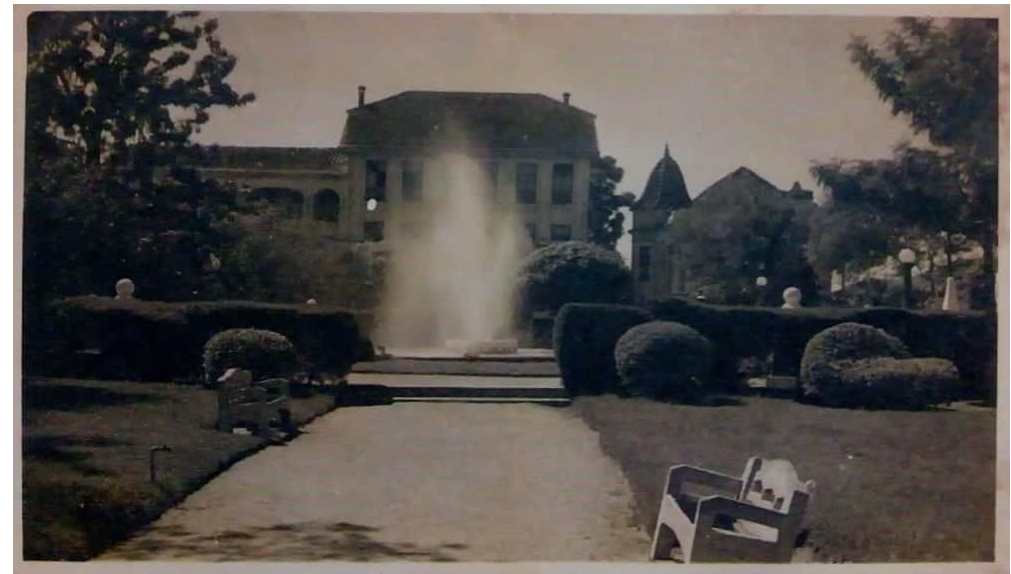

Fonte: Acervo das autoras (Década de 1950).

Em vista disso, algumas das práticas escolares rememoradas pelos entrevistados passavam pelo espaço da praça. Atividades físicas, caminhadas após momentos de refeição, passeios nos turnos de folga das tarefas escolares, além das amizades, conversas, paqueras e táticas para burlar as regras instituídas pela escola, receberam visibilidades no decorrer de suas narrativas.

Ao iniciar a manhã, os alunos realizavam exercícios físicos, denominados por Roswitha Dreher (2017) e Helga Porcher (2017) de "freesport". Estes momentos ocorriam tanto no inverno quanto no verão, e eram realizados na quadra de esportes, na estrada da BR 116 ou em frente à escola, no espaço da Praça do Imigrante: "6 horas, 6 e pouco, o professor plantão abria a porta do dormitório com um apito e apitava e todo mundo tinha que saltar da cama tirar pijama e botar calção e nós íamos fazer educação física matutina" (Hermedo Wagner, 2017).

Enquanto que, nas memórias de Hermedo, essa prática de esporte na praça era uma obrigação em que todos tinham que "saltar da cama", na narrativa de Helga, tal atividade era de livre escolha, sendo uma opção do aluno realizar ou não: "Freesport eu não participava não, porque acordar cedo pra mim sempre foi uma dificuldade" (Helga Porcher, 2017).

Com relação a essas narrativas de memórias, sobre a mesma prática envolvendo o espaço da praça ocorrer de formas distintas, há que se considerar duas possibilidades: uma mudança da norma da instituição na realização desta atividade, ou uma percepção diferente da mesma situação, uma vez que, conforme explica Halbwachs (2003, p. 69), "[...] cada memória individual é um ponto de vista sobre a memória coletiva". Assim sendo, os pontos de vista, as narrações e as lembranças apoiam-se a partir do lugar que o 
sujeito ocupa e das relações que ele estabelece com o meio em que se encontra. $\mathrm{O}$ pesquisador continua explicando que "[...] não é de se surpreender que nem todos tirem o mesmo partido do instrumento comum" (HALBWACHS, 2003, p. 69). Nesse caso, o instrumento comum seria a prática de realizar exercícios na praça no início da manhã.

Outro ponto enfatizado pelos resquícios de memórias dos entrevistados foi em relação aos momentos de caminhada na praça. Esta prática diária, de quinze a trinta minutos, segundo as narrativas, era realizada duas vezes ao dia, após as refeições de almoço e jantar. Roswitha Dreher (2017) explicou essa atividade por meio da expressão "footing". Danilo Streck (2016), ao rememorar essas caminhadas com os colegas na praça, pontuou: “[...] isso é digno de filme". Entretanto, esta atividade não era feita em total liberdade, e existiam regras destinadas ao momento, como recordaram os entrevistados: meninos e meninas da Escola Normal deveriam andar em sentido contrário:

\footnotetext{
"os rapazes iam para o lado direito, as meninas do lado esquerdo [...] podia conversar, mas não era nada recomendado, tu encontrava [alguém] tu dizia 'oi', [os namoros] também ocorriam, mas era no olho né, era no olhar, era, de vez em quando parava para uma conversa, mas era muito raro porque, tinha aquelas sacadas né, tinha professor que morava ali em cima naquelas sacadas, o diretor morava também naquele castelinho, isso né... então tava tudo sob controle" (Danilo Streck, 2016).
}

A escola, fazendo parte de uma estrutura social, pode também ser considerada como uma microssociedade, afirma Escolano Benito (2017). Dessa forma, podemos pensar que as regras, normas e limites, elementos que se encontram articulados entre si e que estabelecem as relações de poder, contribuem no que tange à organização e ao funcionamento de uma instituição educativa.

As voltas na praça foram lembradas aos risos pelos entrevistados, risos provocados pela saudade, ou pela sensação provocada ao se recordarem dos olhares trocados, dos sorrisos encabulados, dos flertes, das sensações em realizar algo de que eles eram privados, ao burlarem a regra imposta pela instituição, sentimentos provocados por aquelas ações que, de alguma forma, a escola lhes proibia, mas que, por outro lado, a praça pública lhes possibilitava. "Lógico que a gente paquerava. Por mais que era proibido, mas a gente está sempre fazendo coisas proibidas, né?” (Helga Porcher, 2017). 
Helga, Roswitha e Celene foram contemporâneas no internato da Escola Normal. Suas narrativas evocam as caminhadas na praça como um momento de enlace em suas amizades, percebendo esse momento na praça como sendo um tempo e um espaço para socializar, para se aproximar uns dos outros. Mesmo que já estivessem o tempo todo junto aos colegas, esse momento diário da praça era indispensável para elas. Segundo Roswitha Dreher (2017), “[...] podia estar chovendo, nós íamos de sombrinha e guardachuva e galocha [...] torreira de sol, nada nos espantava. Era um ponto alto, a gente se produzia". Nessa mesma perspectiva, Celene também rememorou as voltas na praça como uma forma de fortalecimento dos laços afetivos com suas colegas:

\footnotetext{
"E aí a gente tinha então as amizades [...], a gente ia enganchadas de duas, de três, a gente não ia mais de três porque daí era ruim que as meninas iam por um lado $e$ os meninos pro outro, então eu sempre digo assim, a gente passava o dia inteiro na sala de aula e tudo, mas daí quando a gente se encontrava a gente dizia 'oi' (risos). Aí a gente tinha as amigas, digamos eu tinha as minhas amigas, era uma Roswitha e a Helga e a Marlise, que eram nós quatro, aí quase sempre a gente ia de duas em duas que dava mais certo, não ocupava a calçada toda da praça e aí um dia ia com a Helga, um dia com a Roswitha, um dia com a Marlise e assim nós ia trocando, mas nós quatro que era assim, as melhor amigas" (Celene Thoen, 2018).
}

Por conseguinte, essas saídas ao espaço público, as voltas diárias na Praça do Imigrante, eram, nas memórias de Helga Porcher (2017), uma “oportunidade de sair do quadrado". Essa foi uma das práticas realizadas pelos alunos da ENE denominada por eles como uma forma de "liberdade vigiada" que a escola lhes proporcionava. Apesar da regra de meninos e meninas andarem em sentidos opostos na praça, a fim de evitarem contato, os namoros e paqueras eram inevitáveis, e acabavam ocorrendo: "[...] havia uma certa vigilância, que tinha que manter certos limites [...] a comunicação era passar um bilhete [...] se o rapaz ficava parado pra conversar com a moça, isso depois tinha que dar explicação" (Hermedo Wagner, 2017).

De acordo com Arriada, Nogueira e Vahl (2012, p. 51), “[...] ao mesmo tempo que a escola se apresentava como espaço de reclusão, de disciplina e de controle, também era espaço de ruptura, de transgressões, de indisciplina". Assim, não obstante os alunos concordarem com a organização em torno da vigilância, representando-a de forma natural e lógica, os entrevistados não só narraram as regras e condutas exigidas pela ENE, como também contaram, entre risos contidos e tom de voz alternado, as diferentes situações em que agiam contra a regra imposta, ainda que, em algumas ocasiões, a burla 
fosse descoberta. "Mas era no olho, né? Era no olhar"; "a gente ia enganchadas"; "a gente se encontrava, a gente dizia oi", "a comunicação era passar um bilhete”, são fragmentos de memórias narradas, como esses, que nos permitem inferir que o espaço público da Praça do Imigrante se configurava para os alunos da Escola Normal Evangélica enquanto um espaço de sociabilidades, visto que,

[...] a expressão "sociabilidades" remete a práticas interativas que acontecem entre indivíduos, na reprodução do cotidiano. São trocas simbólicas, expressadas a partir de um campo linguístico, ou corporal. Falas, expressões faciais, gestos, olhares, toda uma série de possibilidades que permitem que os indivíduos interajam entre si (FONTES, 2018, p. 167).

Ainda sobre esse aspecto, Helga narrou de que forma percebia a posição da escola: "Eu acho que eles [a escola] faziam de conta que não sabiam, quando a coisa não era muito..., quando não passava dos limites, fingiam que não estavam vendo, mas eu acho que era, assim, uma liberdade vigiada" (Helga Porcher, 2017). Referente a esta expressão “liberdade vigiada”, fazendo alusão à prática da escola envolvendo a Praça do Imigrante, Sampaio (2011) explica que a liberdade é uma parte essencial para que a relação de poder exista. Ou seja, para que o poder possa ser exercido, a liberdade deve se fazer presente; de outra forma, seria uma relação de coação ou inibição, mas não de poder. Segundo Foucault, para a escola,

[...] importa estabelecer as presenças e as ausências, saber onde e como encontrar os indivíduos, instaurar as comunicações úteis, interromper as outras, poder a cada instante vigiar o comportamento de cada um, apreciá-lo, sancionálo, medir as qualidades ou os méritos. Procedimento, portanto, para conhecer, dominar e utilizar. A disciplina organiza um espaço analítico (FOUCAULT, 2014, p. 140).

Nesse sentido, a partir das memórias, podemos inferir que, para os estudantes da Escola Normal, o controle era parte desta liberdade, uma vez que a instituição se fazia presente por meio de uma sensação de estar sendo vigiado. Ou seja, ainda que não houvesse um responsável da escola presente nesses momentos de sociabilidade, os alunos sabiam que estavam sendo avaliados em relação aos seus comportamentos.

Que relação era essa, estabelecida pelos alunos entre a escola e a praça? Quais sentimentos foram despertados quando eles recordaram sobre esse vínculo diário que mantinham entre o espaço público e o privado? No que concerne a este aspecto dos espaços, o pesquisador italiano Portelli (2016, p. 17) nos ajuda a refletir, analisando que 
“[...] a História Oral nos oferece acesso à historicidade das vidas privadas - mas, mais importante ainda, ela nos força a redefinir nossas noções preconcebidas sobre a geografia do espaço público e do privado, e do relacionamento entre eles".

Para além de se apresentar como um "possibilitador de acontecimentos", algo que era barrado nos ambientes internos da escola, mas possibilitado pelos contornos externos da Praça do Imigrante, esse espaço também pode ser traduzido como um local de educação, lazer e sociabilidade. As memórias dos estudantes aqui entrevistados se referiam ao espaço público da praça quase como uma extensão ao espaço privado da Escola Normal, pois as normas, regras e vigilância se estabeleciam em ambos os locais, extrapolando os portões e as paredes da instituição de ensino.

\section{ALGUMAS CONSIDERAÇÕES}

Ao longo do texto, abordamos a Praça do Imigrante em suas dimensões física e espacial com o decorrer do tempo, discutindo as memórias e representações acerca deste local. No decurso do texto, apresentamos e problematizamos as transformações sofridas por tal lugar, cuja aparência foi ganhando novos contornos com o passar dos anos.

O conceito de representação utilizado para a análise das memórias dos entrevistados nos possibilitou compreender o espaço da praça enquanto uma instância de sociabilidade. As nuances entre o espaço público e privado apareceram nas narrativas de forma imbricada, como se a praça pública se tornasse uma extensão do espaço privado da escola. Local este utilizado para educação, na prática de exercícios físicos, lazer, durante as tardes de folga dos alunos e sociabilidade, durante as caminhadas após as refeições, promovendo encontros, comunicação e estreitamento dos laços de amizade entre os estudantes.

Por fim, entendemos que, como um cartão postal da cidade de São Leopoldo, a Praça do Imigrante tem potencial para ser um espaço atrativo e referência no que diz respeito ao patrimônio relacionado à imigração. No entanto, como apontado neste texto, no decorrer do tempo, as mudanças ocorridas na cidade e na praça em si afastaram a população da mesma. Por conseguinte, consideramos que, para que haja um melhor 
Revista do Programa de Pós-Graduação em Educação da Unochapecó

ISSN 1984-1566 (on-line) ISSN 1415-8175 (impressa)

aproveitamento da área, é pertinente que seja concluído o processo de tombamento deste espaço, conforme referido anteriormente.

Desse modo, a difusão dos pressupostos do campo da Educação Patrimonial seria um aliado para melhor aproveitamento da praça na cidade de São Leopoldo, já que ela “[...] é um instrumento de alfabetização cultural que possibilita ao indivíduo fazer a leitura do mundo que o rodeia, levando à compreensão de seu universo sociocultural e da trajetória histórico-temporal na qual está inserido" (REIS; CARDOZO; PRINCIVAL, 2019, p. 215). Com isso, a área em questão seria mais reconhecida e valorizada pelo município e pelos seus habitantes, que teriam maior consciência em relação à sua história e ao modo pelo qual ela é produzida.

\section{REFERÊNCIAS}

ARRIADA, Eduardo; NOGUEIRA, Gabriel Medeiros; VAHL, Mônica Maciel. A sala de aula no século XIX: disciplina, controle, organização. Conjectura, v. 17, n. 2, p. 37-54, maio/ago. 2012.

BRITO, Estela Denise Schütz Brito. Memórias de ex-alunos(as) do internato da Escola Normal Evangélica em São Leopoldo/RS: práticas cotidianas e cultura escolar (1950-1966). 2018. 181 f. Dissertação (Mestrado em Educação) - Universidade do Vale do Rio dos Sinos, São Leopoldo/RS, 2018.

BURKE, Peter. A Escrita da História: Novas Perspectivas. São Paulo: Editora da Universidade Estadual Paulista, 1992.

CARLOS, Ana Fani Alessandri. O Espaço Urbano: novos escritos sobre a cidade. São Paulo: Faculdade de Filosofia, Letras e Ciências Humanas da Universidade de São Paulo, 2007.

CHARTIER, Roger. A História Cultural entre práticas e representações. Rio de Janeiro: Bertrand Brasil, 1990.

CHARTIER, Roger. Defesa e ilustração da noção de representação. Fronteiras, Dourados, v. 13, n. 24, p. 15-29, jul./dez. 2011.

DEMARTINI, Zeila de Brito Fabri. Algumas anotações sobre história de vida e a prática de pesquisa em educação. Revista Pedagógica, Chapecó, v. 15, n. 31, p. 229-247, jul./dez. 2013.

DREHER, Roswitha. Entrevista concedida verbalmente à pesquisa. 2017.

DUARTE, Ariane dos Reis. “O homem que fez 2000 escolas": representações sobre Felipe Tiago Gomes e seu percurso frente à Campanha Nacional de Escola da Comunidade - 
Revista do Programa de Pós-Graduação em Educação da Unochapecó

ISSN 1984-1566 (on-line) ISSN 1415-8175 (impressa)

CNEC (1940-2000). 2019. 177 f. Tese (Doutorado em Educação) - Universidade do Vale do Rio dos Sinos, São Leopoldo / RS.

ESCOLANO BENITO, Augustín. A escola como cultura: experiência, memória e arqueologia. Campinas: Alínea, 2017.

FONTES, Breno Augusto Souto-Maior. Os espaços de sociabilidade na construção dos territórios. Revista Brasileira de Gestão e Desenvolvimento Regional, Taubaté/SP, v. 14, n. 4, p. 165-179, jul. 2018 (ed. especial).

FOUCAULT, Michel. Vigiar e punir: nascimento da prisão. 42. ed. Petrópolis: Vozes, 2014.

HALBWACHS, Maurice. A memória coletiva. São Paulo: Centauro, 2003.

HOPPEN, Arnildo. Formação de professores evangélicos no Rio Grande do Sul I Parte (1909-1939). São Leopoldo: Sinodal, [19--?].

LE GOFF; Jacques; NORA, Pierre. História: novos problemas. Rio de Janeiro: F. Alves, 1974.

MAGALHÃES, Magna Lima. Entre a preteza e a brancura brilha o Cruzeiro do Sul: associativismo e identidade negra em uma localidade teuto-brasileira. 2010. 219 f. Tese (Doutorado em História) - Universidade do Vale do Rio dos Sinos, São Leopold/RS.

MAUAD, Ana Maria. Na mira do olhar: um exercício de análise da fotografia nas revistas ilustradas cariocas, na primeira metade do século XX. Anais do Museu Paulista, São Paulo, v. 13, n. 1, p. 133-174, jan./jun. 2005. Disponível em:

<https://www.scielo.br/pdf/anaismp/v13n1/a05v13n1.pdf >. Acesso em: 04 mai. 2020.

MAYBORODA, Fabiana Gazzotti. Os Jardins de Recreio em Porto Alegre / RS: uma análise da relação entre a política pública e a constituição de uma Educação na República (1920 a 1950). 2017. 149 f. Dissertação (Mestrado em Educação) - Universidade do Vale do Rio dos Sinos, São Leopoldo / RS.

MENESES, Ulpiano T. Bezerra de. Fontes visuais, cultura visual, História visual. Balanço provisório, propostas cautelares. Revista Brasileira de História, São Paulo, v. 23, n. 45, p. 11-36, 2003.

NORA, Pierre. Entre memória e história - a problemática dos lugares. Projeto História, Revista do Programa de Estudos Pós-Graduados em História e do Departamento de História da PUC-SP, São Paulo, dez. 1993.

PORCHER, Helga. Entrevista concedida verbalmente à pesquisa. 2017.

PORTELLI, Alessandro. História oral como arte da escuta. São Paulo: Letra e Voz, 2016. 
Revista do Programa de Pós-Graduação em Educação da Unochapecó

ISSN 1984-1566 (on-line) ISSN 1415-8175 (impressa)

REIS, Diego Geovan; CARDOSO, Poliana Fabíula; PRINCIVAL, Viviane Cristina. Educação patrimonial no contexto da pedagogia histórico-crítica: aproximações epistemológicas. Revista Pedagógica, Chapecó, v. 21, p. 210-227, 2019.

SAMPAIO, Simone Sobral. A liberdade como condição das relações de poder em Michel Foucault. Rev. Katálysis [online], v. 14, n. 2, p .222-229, 2011.

SANTOS, Milton. Espaço e sociedade: ensaios. Petrópolis: Vozes, 1979.

SANTOS, Milton. Por uma geografia nova: Da crítica da geografia a uma geografia crítica. São Paulo: Editora da Universidade de São Paulo, 2004.

SIMMEL, George. O problema da sociologia. In: MORAES FILHO, Evaristo de (Org.). Georg Simmel: Sociologia. São Paulo: Ática, 1983. (Col. Grandes Cientistas Sociais, vol. 34).

STRECK, Danilo. Entrevista concedida verbalmente à pesquisa. 2016.

THOEN, Celene. Entrevista concedida verbalmente à pesquisa. 2018.

THOMPSON, Paul. A voz do passado: história oral. Rio de Janeiro: Paz e Terra, 1992.

TRAVI, Otávio Augusto Klein. Ensino de história local e memórias silenciadas: o bairro África em Novo Hamburgo (RS). 2018. 75 f. Trabalho de conclusão de curso (Graduação em História) - Universidade Federal do Rio Grande do Sul / UFRGS, Porto Alegre / RS.

VOLDMAN, Danièle. A invenção do depoimento oral. In: AMADO, Janaína; FERREIRA, Marieta de Moraes (Orgs.). Usos e abusos da História Oral. 8. ed. Rio de Janeiro: Fundação Getúlio Vargas, 2006.

WAGNER, Hermedo. Entrevista concedida verbalmente à pesquisa. 2017.

WEBER, Roswithia. Praça Centenário e seu monumento: persistência do nacionalismo no pós Segunda Guerra Mundial - São Leopoldo/RS. Patrimônio e Memória, São Paulo, v. 12, n. 1, 2016.

XAVIER, Libânea Nacif. O debate em torno da nacionalização do ensino na Era Vargas. Educação, Santa Maria, v. 30, n. 2, p. 105-120, 2005.

Enviado em: 05-06-2021

Aceito em: 03-07-2021

Publicado em: 05-08-2021 